\title{
Multiple forms of alkaline phosphatase in mouse preimplantation embryos
}

\author{
J. Kim, H. K. Kim, K. Kim, S. R. Kim* and W. K. Cho \\ Department of Zoology, College of Natural Sciences, Seoul National University, and \\ * College of Medicine, Ewha Woman's University, Seoul, Korea
}

\begin{abstract}
Summary. Mouse embryos were extracted with $0.5 \%$ Triton X-100 and subjected to cellulose acetate electrophoresis. In fertilized eggs, two forms of alkaline phosphatase (ALP), a slow-moving form and a fast-moving form, were observed. As cleavage proceeded, the fast-moving form disappeared, and the slow-moving form, the mobility of which was similar to that of the slow-moving form of the kidney, became gradually dominant up to the blastocyst stage (named 'embryonic' form). With blastulation, another fast-moving form showing a similar mobility to the lung ALP began to appear in blastocysts and showed a transient dominance in hatched blastocysts. After implantation, both the embryonic form and the fast-moving form gradually faded, and were eventually replaced by the new form, which may be named 'fetal form' in Day 7 embryos.

These results clearly demonstrated that ALP activity does exist in embryos at all stages of preimplantation development. Moreover, the changes in multiple forms of ALP correlated with embryonic development may suggest that these multiple forms may have differential roles in the process of early development.
\end{abstract}

Keywords: alkaline phosphatase; isoenzymes; preimplantation mouse embryo; cellulose acetate electrophoresis

\section{Introduction}

Alkaline phosphatase (ALP, orthophosphomonoester phosphohydrolase, EC 3.1.3.1) in mammals is known to have multiple, tissue-specific forms (McComb et al., 1979). Even in the same tissue, different forms of ALP have been observed at different developmental stages (McComb et al., 1979; Merchant-Larios et al., 1985). Of these multiple forms, four isoenzymes of ALP have been identified previously (Fishman, 1974; Mueller et al., 1985).

ALP in mammalian preimplantation embryos has been studied since Mulnard's (1955) first report. There are, however, few reports dealing with the isoenzyme types and the pattern of multiple forms of ALP in embryos, perhaps because of its low activity in embryos and the logistics of collecting embryos. Previous studies on ALP in mammalian preimplantation embryos were focussed on the time of onset and the localization of the ALP activity (Sherman, 1979). These studies were mainly performed by cytochemistry, but a few biochemical studies, including electrophoresis and spectrophotometry, have been reported (Sherman, 1972; Izquierdo \& Marticorena, 1975).

The present experiment adopted some modifications in methods of extraction and electrophoresis in order to enhance electrophoretic sensitivity for detection of ALP, and investigated the electrophoretic mobility of ALP detectable in preimplantation mouse embryos and its change in activity during early embryogenesis. The existence of ALP activity in embryos at early cleavage stages was also investigated by electrophoresis and spectrophotometry. 


\section{Materials and Methods}

Sampling. Fertilized eggs and embryos were obtained from superovulated ICR mice $>2$ months of age, which were bred randomly at the Seoul National University Animal Breeding Center. Female mice were intraperitoneally injected with 5 i.u. PMSG (Folligon; Intervet International B.V., Boxmeer, The Netherlands) and followed by 5 i.u. hCG (Chorulon; Intervet) $48 \mathrm{~h}$ later. The day of hCG injection was designated as Day 0 of pregnancy. Preimplantation embryos were flushed out from oviduct or uterus at various times; fertilized eggs at $24 \mathrm{~h}$, early 2 -cell embryos at $40 \mathrm{~h}$, late 2-cell embryos at $48 \mathrm{~h}, 4$-cell embryos at $56 \mathrm{~h}, 8$-cell embryos at $72 \mathrm{~h}$, morulae at $80-90 \mathrm{~h}$, early blastocysts at $90-94 \mathrm{~h}$, late blastocysts at $100 \mathrm{~h}$, and hatched blastocysts at $120 \mathrm{~h}$ after hCG injection. Post-implantation embryos were dissected out from the decidua (Hogan et al., 1986). Harvested embryos were washed more than 3 times with fresh medium (SECM: Standard Egg Culture Medium; Biggers et al., 1971). Embryos at each stage were collected by means of a mouth-controlled capillary pipette pre-filled with $10 \mu \mathrm{l} 0.25 \mathrm{M}$-sucrose (Sigma Chemical Co., St Louis, MO, USA) solution, and pooled as follows for electrophoretic analysis: 200 for each group of fertilized eggs, early and late 2-cell embryos, 50-100 embryos in each group for embryos from the 4-cell stage to the blastocyst, and 10-50 embryos in each group for the later embryos. Samples were then stored at $-20^{\circ} \mathrm{C}$ in $1 \cdot 5-\mathrm{ml}$ microtubes (Eppendorf, Hamburg, W. Germany).

Serum and organs such as kidney, lung, intestine and liver were obtained from pregnant mice at Day 4, and placenta at Day 15 of gestation. These organs were washed with saline $(0.9 \%(\mathrm{w} / \mathrm{v}) \mathrm{NaCl}$ in distilled water) to remove blood contaminant, and stored at $-20^{\circ} \mathrm{C}$ until use.

Extraction of $A L P$. Embryos were disrupted by several repetitions of freezing-thawing. Samples were added with $5 \mu \mathrm{l}$ Triton X-100 solution diluted in $0.25 \mathrm{M}$-sucrose (final concentration, $0.5 \%$ ) and vortexed intermittently (5-10 min intervals) for $60 \mathrm{~min}$. When $n$-butanol (Tedia Co., Inc, Fairfield, OH, USA) was tested, it was added to samples with the Triton X-100 solution. Then the samples were centrifuged at $10000 \mathrm{~g}$ for $10 \mathrm{~min}$ at $4^{\circ} \mathrm{C}$, and stored at $-20^{\circ} \mathrm{C}$.

ALP in adult organs was extracted by the modified procedure of Smith et al. (1968). The supernatant of homogenates was treated with $n$-butanol (final concentration, $20 \%$ ) and/or Triton X-100 solution (final concentration, $0 \cdot 5 \%$ ). The sample tubes on ice were vortexed intermittently for $60 \mathrm{~min}$. Samples were then centrifuged at $10000 \mathrm{~g}$ for $60 \mathrm{~min}$ at $4^{\circ} \mathrm{C}$. After centrifugation, separated aqueous layers were taken as enzyme extracts and kept frozen at $-20^{\circ} \mathrm{C}$.

Electrophoresis. Electrophoresis was performed according to the method of Fritsche \& Adams-Park (1972) with some minor modifications. Triton X-100 (final concentration, $0.5 \%$ ) was mixed in the running buffer $(0.067 \mathrm{M}$-Trisbarbital solution, $\mathrm{pH} 8.9$ at $25^{\circ} \mathrm{C}$ ). A microzone microelectrophoresis kit (Beckman Instruments Ltd, Fullerton, CA, USA) was adopted for electrophoretic analysis. The enzyme extract was applied with a slit applicator (Beckman) on the cellulose acetate membrane (Gelman Sciences, Ann Arbor, MI, USA) 1-5 times $(0 \cdot 2-1 \cdot 0 \mu 1)$, and electrophoresed at $200 \mathrm{~V}$ for $30 \mathrm{~min}$ with $\sim 4 \mathrm{~mA}$ of initial current. The blank was a sample devoid of embryos. After running started, $10 \mathrm{ml}$ buffered agar $(1 \%)$ were melted and cooled to $45^{\circ} \mathrm{C}$, then mixed homogeneously with a mixture of $0.5 \mathrm{ml}$ naphthol AS-MX phosphate solution ( $2 \mathrm{mg} / \mathrm{ml}$ in $3 \mathrm{M}$-Tris; Sigma) and 1.0 ml 2-AMP (2-amino-2-methyl-1-propanol; Sigma) buffer $\left(2 \mathrm{M}, \mathrm{pH} 8.8\right.$ at $25^{\circ} \mathrm{C}$ ) (Bergerman \& Blethen, 1972). The substrate-agar was gelled into a thin sheet in a small plastic tube, which is a little wider than the size of membrane. The buffered agar was prepared by melting $1 \mathrm{~g}$ agar (Difco West Molesey, Surrey, UK) in $100 \mathrm{ml}$ 2-AMP buffer ( $2 \mathrm{M}, \mathrm{pH} 8.8)$ and stored at $3^{\circ} \mathrm{C}$ in $10 \mathrm{ml}$ samples.

After running, the cellulose acetate membrane was blotted thoroughly, allowed to cling to the substrate-gel upside down and incubated at $37^{\circ} \mathrm{C}$ for $30 \mathrm{~min}$ for the enzyme reaction. Incubation time was prolonged to $60 \mathrm{~min}$ when the enzyme activity was very low. After incubation, the membrane was detached from the substrate-gel and dried. The banding pattern of the enzyme activity was visualized with a u.v. transilluminator and photographed on polaroid type 667 film (Polaroid Ltd, Hertfordshire, UK).

Spectrophotometry. The total activity of ALP in embryos was spectrophotometrically measured by the procedure of Bretaudiere et al. (1977) with a slight modification. The reaction was allowed at $37^{\circ} \mathrm{C}$ for 90 min and stopped by adding $0.9 \mathrm{ml} 0.5 \mathrm{~N}$ cold $\mathrm{NaOH}$ solution. Standard and blank were the same as the enzyme samples except that the former was added with $p$-nitrophenol (Sigma) and the latter with distilled water instead of enzyme extract in the enzyme samples. The sensitivity of this assay was $0.25 \mathrm{nmol} / \mathrm{ml}$, and the mean coefficient of variation for 8 separated pools was $3.9 \pm 1.4 \%$.

\section{Results}

\section{Effect of extraction reagents on electrophoretic patterns}

To compare differences in extraction efficiency and electrophoretic resolution by extraction reagents, blastocysts and kidney from adult mice were extracted with $n$-butanol, Triton X-100 and the combination of $n$-butanol and Triton X-100 (n-butanol/Triton X-100) respectively. As shown in Fig. 1, ALP activity of the blastocyst sample extracted with $n$-butanol was quite low when compared with samples extracted with other reagents. On the other hand, both the samples 
extracted with $n$-butanol/Triton X-100 and the one extracted with Triton X-100 alone showed clear bands of ALP. The electrophoretic mobility of the ALP in blastocysts extracted with different reagents did not show any marked differences.

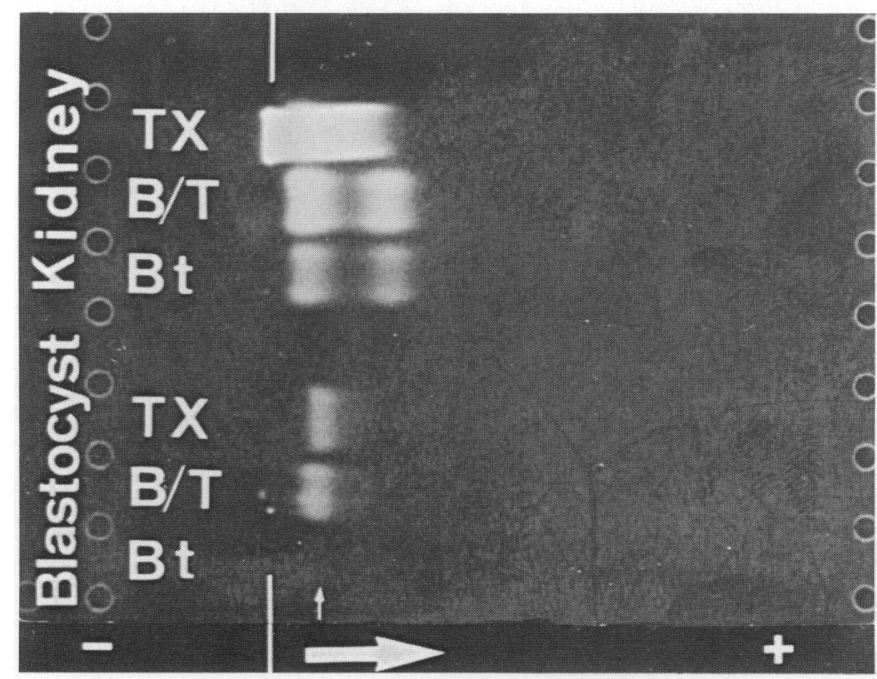

Fig. 1. Comparison of electrophoretic patterns between samples extracted with different reagents. The volume of extract approximately equivalent to 2 late blastocysts was applied for embryo samples. The vertical line marks the application point and the horizontal arrow indicates the direction from cathode $(-)$ to anode $(+)$. The small vertical arrow indicates the weak band of $\mathrm{ALP}$ activity in the lane. $\mathrm{Bt}=$ extracted with $20 \% n$-butanol; $\mathrm{B} / \mathrm{T}=$ extracted with $20 \% n$-butanol and $0.5 \%$ Triton X-100; TX $=$ extracted with $0.5 \%$ Triton X-100.

The kidney sample extracted with $n$-butanol alone showed activity that was a little lower than those samples prepared with the other reagents. However, the electrophoretic resolution of the enzyme in this sample was superior to that of the others. The sample extracted with Triton X-100 alone showed a poor resolution and decreased electrophoretic mobility, while the sample extracted with $n$-butanol/Triton X-100 was satisfactory for both activity and resolution. On the basis of these results, the embryos were extracted with $n$-butanol/Triton X-100, and the electrophoretic mobility of ALP in embryos was compared with that in various adult organs. In addition, embryos were treated with Triton X-100 alone, and electrophoretic mobility of ALP was examined as a function of stages during early embryogenesis.

\section{Blastocyst $A L P$ and organ $A L P$}

Figure 2 depicts the electrophoretic mobility of ALP in blastocysts and various adult organs treated with $n$-butanol/Triton X-100. Each organ showed a characteristic form or forms of ALP; serum, lung and liver had a single specific form, intestine and kidney, two forms and placenta, three forms. Although ALP activities in serum and intestine were relatively weak, their band patterns could be identified. Blastocysts also showed two bands; the slow-moving form which is the main band and the mobility of which was mostly similar to that of the kidney ALP, and the fast-moving form which was similar to the lung ALP with weak activity. 


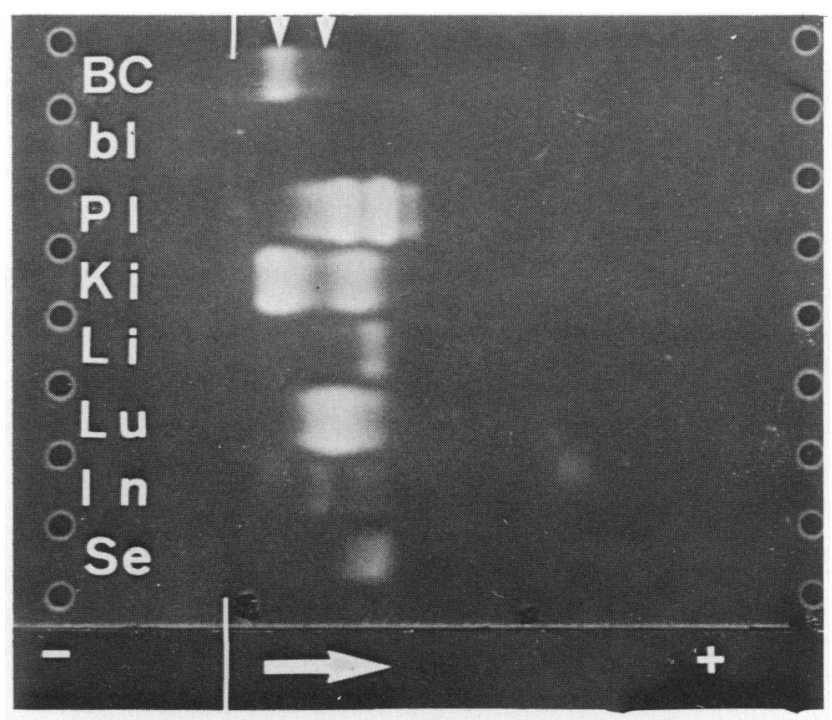

Fig. 2. Comparison of the electrophoretic mobility of ALP between blastocysts and various adult organs. Each sample was extracted with $20 \% n$-butanol and $0.5 \%$ Triton X-100. The 2 arrows indicate the two forms of ALP in blastocysts. Se = serum; In = intestine; Lu = lung; $\mathrm{Li}=$ liver; $\mathrm{Ki}=$ kidney; $\mathrm{Pl}=$ placenta; $\mathrm{BC}=$ late blastocyst $(4$ embryos $) ;$ and $\mathrm{bl}=$ blank.

\section{Changes in multiple forms of ALP during early embryogenesis}

The slow-moving form of ALP appeared in all embryos at any stage of preimplantation development, including fertilized eggs (Fig. 3). It may therefore be called the 'embryonic' form. This form was observed at first in fertilized eggs and the activity became gradually dominant up to the blastocyst stage as cleavage proceeded. In fertilized eggs, the third form of trace activity was detected and it lasted up to the 4-cell stage (Fig. 4). This form was also observed in oocytes as a clear-cut band (unpublished data). The fast-moving form of ALP in blastocysts appeared at first in a diffused band ahead of embryonic form in early blastocysts (Fig. 5). In hatched blastocysts, the fast-moving form made a discrete band, while the embryonic form began to weaken. The fastmoving form faded in Day-6 embryos after implantation and along with the embryonic form was finally replaced by a new fourth form of ALP, the mobility of which was between the two other forms (Fig. 5). It may be called the 'fetal' form since it was maintained at least up to the Day-12 fetus and mobility was not affected by $n$-butanol extraction (unpublished data).

The spectrophotometric measurement of the total activity of ALP showed a minimum value $(1.67 \pm 0.60 \mathrm{pmol} / \mathrm{h} / \mathrm{egg})$ in fertilized eggs and exponential augmentation as the number of blastomeres increased (Fig. 6). The increasing rate of total ALP activity surpassed the rate of increase in cell number, at least up to the 8-cell embryo.

\section{Discussion}

There have been a number of studies to detect ALP activity in mammalian preimplantation embryos by means of cytochemical analysis. Vorbrodt et al. (1977) observed the ALP activity in fertilized eggs, but not in the later embryos until the 8-cell stage. On the other hand, Mulnard \& Huygens (1978) and Ziomek \& Lepire (1984) reported the onset of ALP activity only after the 2-cell stage, while other investigators failed to detect ALP activity until 4-cell embryos (Izquierdo \& Marticorena, 1975; Ishiyama \& Izquierdo, 1977; Izquierdo et al., 1980) or up to the 8-cell stage 


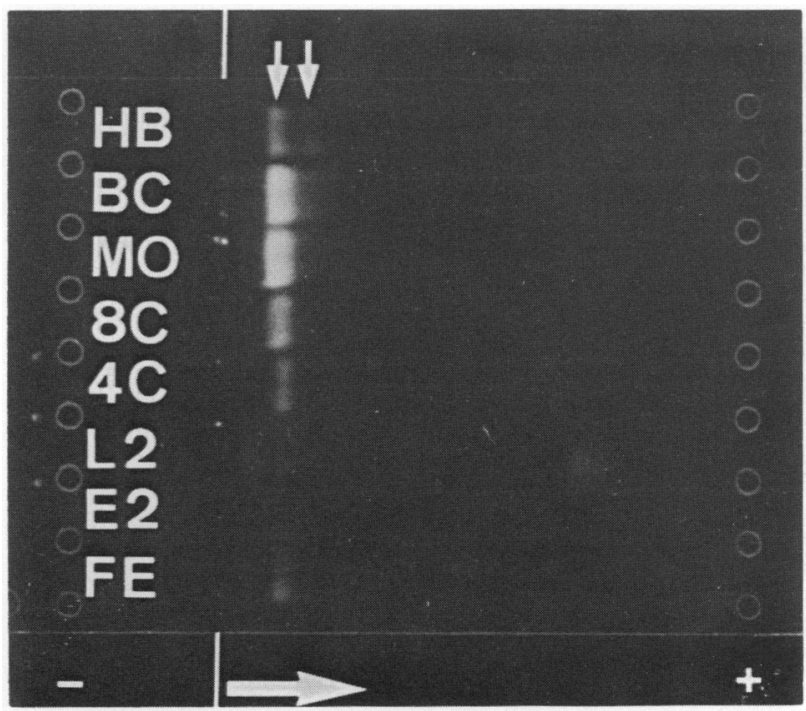

Fig. 3. Changes in embryonic form of ALP during preimplantation development. Each sample was extracted with $0.5 \%$ Triton X-100 alone. The 2 vertical arrows indicate the two forms of ALP in the hatched blastocyst. The slow-moving, 'embryonic' form was detected in embryos at all stages of embryogenesis. The amounts of sample applicd to each lane were as follows; 13-14 eggs or embryos for fertilized eggs (FE) and early 2-cell embryos (E2); 6-7 cmbryos for late 2-cell embryos (L2), 4-cell embryos (4C), 8-cell embryos (8C), morulae (MO), and late blastocysts (BC); and 3-4 embryos for hatched blastocysts (HB) respectively.

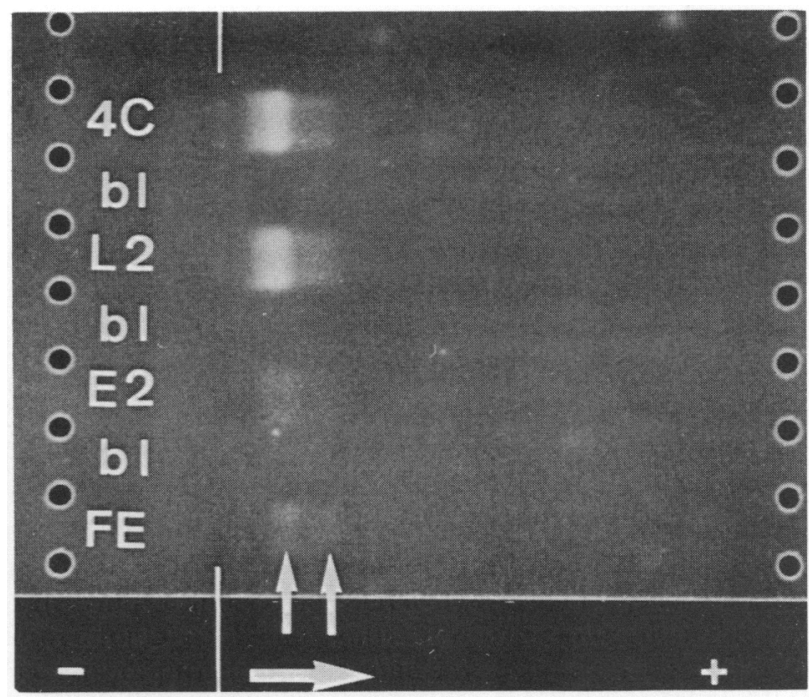

Fig. 4. Two forms of ALP in fertilized eggs. About 13-14 embryos were applied to each lane. Blank samples were applied between the sample lanes to rule out the possibility of contamination by the applicator. The reaction time was prolonged to $60 \mathrm{~min}$ to enhance the band intensity. One of the two vertical arrows indicates the 'embryonic' form (slow-moving) and the third fast-moving form of ALP in fertilized cggs. The fast-moving form lasted to the 4-cell stage. $\mathrm{FE}=$ fertilized eggs; $\mathrm{E} 2$ = early 2-cell embryos; $\mathrm{L} 2$ = late 2-cell embryos; $4 \mathrm{C}=4$-cell cmbryos; and $\mathrm{bl}=$ blank. 


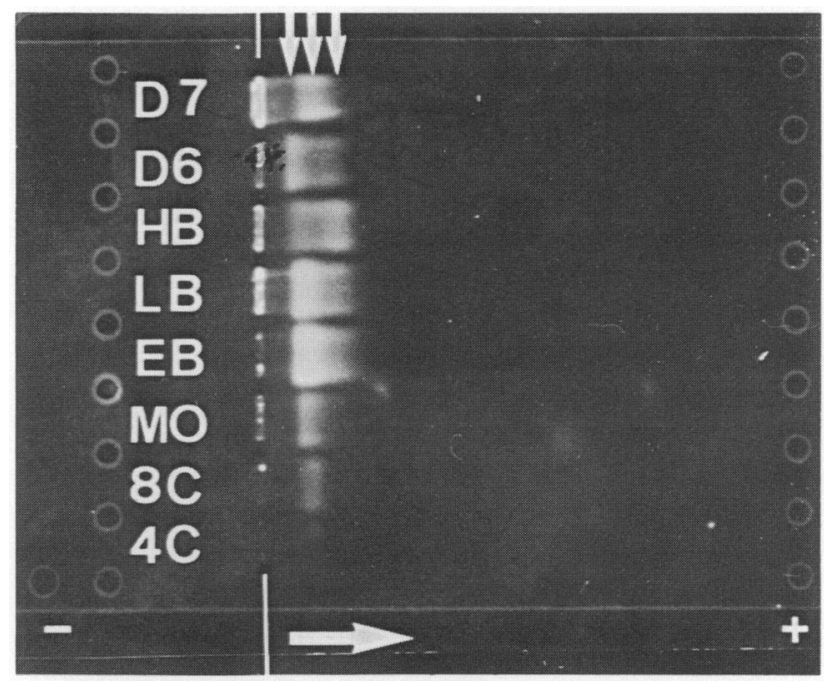

Fig. 5. Changes in multiple forms of ALP during peri-implantation development. The equivalent of 3 embryos was applied to each lane except that for Day -7 embryos ( $<1$ embryo). The 3 vertical arrows indicate the 3 forms of ALP that appeared during peri-implantation development. Both the slow-moving and the fast-moving form in blastocysts were replaced by a new, 'fetal' form of medium mobility. $4 \mathrm{C}=4$-cell embryos; $8 \mathrm{C}=8$-cell embryos; $\mathrm{MO}=$ morulae; $\mathrm{EB}=$ early blastocysts; $\mathrm{D} 6=$ Day 6 embryos; and D7 $=$ Day 7 embryos.

(Johnson et al., 1977). By using electrophoresis, Sherman (1972) found ALP activity in Day 10 mouse embryos extracted with Tween 80, but failed to detect ALP activity in blastocysts extracted with $n$-butanol. It appears then that the extraction reagent may be important for detection of ALP activity in early embryos. Indeed, $n$-butanol seems to inhibit ALP activity (Pfohl, 1975). It is evident that clear bands of ALP activity in blastocysts and kidney were produced by treatment with Triton X-100 or with a mixture of Triton X-100 and $n$-butanol. However, application of $n$-butanol alone was insufficient to reveal the ALP band of blastocysts (Fig. 1). It is also evident that application of Triton X-100 greatly enhanced the sensitivity of spectrophotometric analysis in embryos when compared with previous results (Izquierdo \& Marticorena, 1975; Cho et al., 1984). The present data are similar to the studies by Soucek \& Vary (1984) who observed the enhancing effect of Triton X-100 on ALP activity. Triton X-100 influenced substantially electrophoretic resolution of the enzyme in the present experiment as well as in other studies although different matrices were used (Coutinho et al., 1966; Singh \& Wasserman, 1970; Pourci et al., 1984). A running buffer devoid of Triton X-100 resulted in a poor resolution and mobility of the ALP. Application of Triton X-100, a non-ionic detergent like Tween 80 , therefore seems to be important for extraction and electrophoretic analysis of ALP, particularly for preimplantation embryos.

Consequently, Triton X-100 was used as the extraction reagent throughout the experiments. The existence of ALP activity in embryos at the earliest stages, i.e. fertilized eggs to the late blastocyst, was confirmed in the present study by using electrophoresis. The sensitivity was sufficient to show the clear-cut band of ALP activity even for as few as 2 blastocysts. The present data would resolve the long-standing controversy over the specific stage of the embryos at which the ALP activity can be detected. Together with electrophoretic results, the total ALP activity in fertilized eggs measured by spectrophotometry showed a significant value and its activity increased rapidly as cleavage proceeded with a well-ordered second-order curve from as early as the fertilized egg stage. This figure was in contrast with the previous results (Izquierdo \& Marticorena, 1975). 

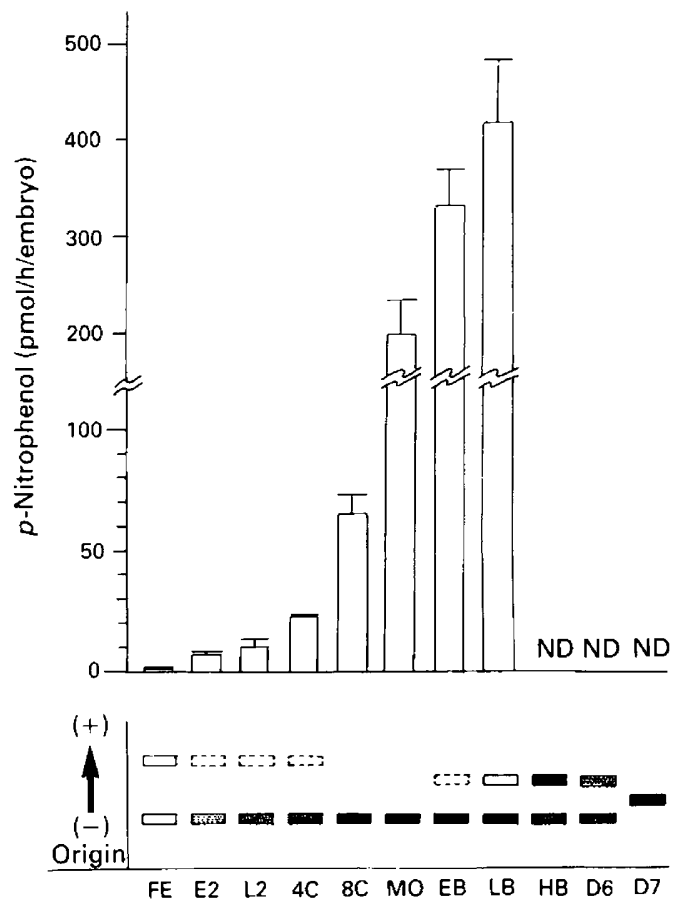

Fig. 6. The total ALP activity measured by spectrophotometry. Changes in multiple forms of ALP during early embryogenesis are summarized in parallel to changes in the total ALP activity. For the assay, 150 eggs or embryos were used for fertilized eggs (FE), early 2-cell (E2) and late 2-cell (L2) embryos, 50 embryos for 4-cell (4C), early (EB) and late blastocysts (LB). Hatched blastocysts (HB), Day-6 embryos (D6) and Day-7 embryos (D7) were not determined (ND). Each value is the mean \pm s.e. of 3 measurements.

The 4 different forms of ALP observed in the present study are summarized in Fig. 6. Among them, the fast-moving form detected in fertilized eggs and the slow-moving form, e.g. the "embryonic' form, seem to be only the remnant of the ALP that existed in oocytes which was the same form observed as a clear band through all phases of oocyte maturation (unpublished data). Another fast-moving form, newly appearing in embryos with blastulation, may be related to the differentiation of embryonic tissues and trophectoderm, as suggested by Mulnard \& Huygens (1978) on the basis of differential localization of ALP in blastocysts. The transient enhancement of the fast-moving form of ALP just around the time of hatching suggests that this form may play an important role in the process of hatching at implantation. Both the embryonic form and the fastmoving form were replaced by the single 'fetal' form after Day 7 when the embryo became more differentiated. The fetal form of ALP is comparable with a single form detected in the various fetal organs up to Day 13 of gestation, hence the name "embryonic ALP isoenzyme" (Merchant-Larios et al., 1985). The sudden change in ALP form in Day-7 embryos may reflect some developmental transition in the embryo, although further detailed study should define the functions of these multiple forms of ALP. The correlation between change in the multiple forms and developmental process suggests that these multiple forms may have a differential role in the regulation of embryonic development. It is quite unusual that 4 kinds of multiple forms of an enzyme were detected in the mammalian embryo during early embryogenesis (Auerbach \& Brinster, 1967). These multiple forms might be derived from modification of an isoenzyme or from expression of different

forms al ALP :ell (E2) $S(L B)$. irmined genes. 
Although the present experiment compared the electrophoretic mobility of the multiple forms of ALP in embryos with that of various adult organs, it is just a start to the characterization of the enzyme. To examine further the isoenzyme type or types of these multiple forms, many characteristics such as specificity, physicochemical properties and immunoreactivity should be investigated (for review, see Fishman, 1974).

This study was in part supported by grants from the Korea Science and Engineering Foundation (KOSEF, 1986) to W.K.C. and from the Research Council of Applied Genetics (1985) to S.R.K.

\section{References}

Auerbach, S. \& Brinster, R.L. (1967) Lactate dehydrogenase isozymes in the early mouse embryo. Expl Cell Res. 46, 89-92.

Bergerman, J. \& Blethen, S. (1972) Determination of alkaline phosphatase isozymes. Clin. Chim. Acta 36, 389-396.

Biggers, J.D., Whitten, K.W. \& Whittingham, D.G. (1971) The culture of mouse embryos in vitro. In Methods in Mammalian Embryology, pp. 76-116. W. H. Freeman \& Co., San Francisco.

Bretaudiere, J-P., Vassault, A., Amsellem, L., Poucl, M-L., Thieu-Phung, H. \& Baully, M. (1977) Criteria for establishing a standardized method for determining alkaline phosphatase activity in human serum. Clin. Chem. 23, 2263-2274.

Cho, W.K., Lee, C.C. \& Kim, H.K. (1984) A study of alkaline phosphatase activity on the preimplantation embryo. Korean J. Zool. 27, 1-12.

Coutinho, H.B., Katchburian, E. \& Pearse, A.G.E. (1966) Effects of Triton X-100 upon the mobility of esterases and alkaline phosphatases in disc electrophoresis. $J$. clin. Path. 19, 617-618.

Fishman, W.H. (1974) Perspective on alkaline phosphatase isozymes. Am. J. Med. 56, 671-650.

Fritsche, H.A., Jr \& Adams-Park, H.R. (1972) Cellulose acetate electrophoresis of alkaline phosphatase isozymes in human serum and tissue. Clin. Chem. 18, 417-421.

Hogan, B., Constantini, F. \& Lacy, E. (1986) Isolating postimplantation-stage embryos. In Manipulation of the Mouse Embryo, pp. 115-121. Cold Spring Harbor Laboratory.

Ishiyama, V. \& Izquierdo, L. (1977) The onset of phosphatase activity in early mammalian embryos. $J$. Embryol. exp. Morph. 42, 305-308.

Izquierdo, L. \& Marticorena, P. (1975) Alkaline phosphatase in preimplantation mouse embryos. Expl Cell. Res. 92, 399-402.

Izquierdo, L., Lopez, T. \& Marticorena, P. (1980) Cell membrane regions in preimplantation mouse embryos. J. Embryol. exp. Morph. 59, 89-102.

Johnson, L.V., Calarco, P.G. \& Siebert, M.L. (1977) Alkaline phosphatase activity in the preimplantation mouse embryo. J. Embryol. exp. Morph. 40, 83-89.

McComb, R.B., Bowers, G.N., Jr \& Posen, S. (1979) Isozymes. In Alkaline Phosphatase, pp. 373-524. Plenum Press, New York.

Merchant-Larios, H., Mendlovic, F. \& Alkvarez-Buylla, A. (1985) Characterization of alkaline phosphatase from primordial germ cells and ontogenesis of this enzyme in the mouse. Differentiation 29, 145-151.

Mueller, H.D., Leung, H. \& Stinson, R.A. (1985) Different genes code for alkaline phosphatase from human fetal and adult intestine. Biochem. Biophys. Res. Commun. 126, 427-433.

Mulnard, J. (1955) Contribution a la connaissance des enzymes dans l'ontogenese les phosphomonoesterases acied et alkaline dans le development du rat et la souris. Archs Biol. (Paris) 66, 528-688.

Mulnard, J. \& Huygens, R. (1978) Ultrastructural localization of non-specific alkaline phosphatase during cleavage and blastocyst formation in the mouse. $J$. Embryol. exp. Morph. 44, 121-131.

Pfohl, R.J. (1975) Alkaline phosphatase of sea urchin embryos; Chromatographic and electrophoretic characterization. Devl Biol. 44, 333-345.

Pourci, M.L., Cherruau, B. \& Lacour, B. (1984) Determination of placental alkaline phosphatase phenotypes by starch-gel and acrylamide gel electrophoresis. Clin. Chim. Acta 1410, 1-8.

Sherman, M.I. (1972) The biochemistry of differentiation of mouse trophoblast: Alkaline phosphatase. Devl Biol. 27, 337-350.

Sherman, M.I. (1979) Developmental biochemistry of pre-implantation mammalian embryos. Annls Biochem. 48, 443-470.

Singh, J. \& Wasserman, A.R. (1970) Detection of aggregation and nondestructive disaggregation of membranous proteins using polyacrylamide gel electrophoresis with non-ionic detergents. Biochim. Biophys. Acta 221, 379-382.

Smith, I., Lightstone, P.J. \& Perry, J.D. (1968) Separation of human alkaline phosphatases by electrophoresis on acrylamide disc gels. Clin. Chim. Acta 19, 499-505.

Soucek, D.A. \& Vary, J.C. (1984) Some properties of acid and alkaline phosphatases in boar sperm plasma membranes. Biol. Reprod. 31, 687-693.

Vorbrodt, A., Konwinski, M., Solter, D. \& Koprowski, H. (1977) Ultrastructural cytochemistry of membranebound phosphatases in preimplantation mouse embryos. Devl Biol. 55, 117-134.

Ziomek, C.A. \& Lepire, M. (1984) The fluorescent histochemical demonstration of alkaline phosphatase in pre-implantation mouse embryo. J. Cell Biol. 99, 227a, Abstr. 